\title{
TEACHING INDIVIDUAL DIFFERENCES
}

\author{
Rodney L. Lowman, Donald F. Parker, and L. Delf Dodge \\ The University of Michigan
}

Instructors of Organizational Behavior, regardless of their institutional setting, often face the problem of having to teach a considerable amount of theory-based material about human behavior in organizations in a time span which does not permit detailed explanation of the theories, their application, and implications. This difficulty may be complicated, particularly in professional schools, by the presence of many students who may hold the more quantitative and procedureoriented disciplines in higher regard. Often, such students actively resist $\mathrm{OB}$ courses, categorizing them as impractical, "too theoretical," or just "common sense."

This resistance can sometimes be quickly and often permanently reduced through forceful demonstrations of the existence, relevance, and importance of the phenomena which the discipline seeks to understand. Such a demonstration is especially valuable if it occurs early in the term, before prior biases are reinforced. Because many $O B$ instructors begin their courses with a discussion of individual differences, this subject is particularly well suited for the type of demonstration we suggest. In our experience, psychological theories relating to personality and other individual level phenomena often encounter especially strong criticism from students of Organizational Behavior. The objections appear to be based, in part, on the fact that some of the individual theories of personality presented in OB theories or introductory texts (e.g., such typological theories as those of Jung and Freud) are in fact of limited relevance to organizational settings (at least as they are experienced by practicing managers). The usefulness of the personality concept may therefore be rejected entirely before its considerable potential for helping students understand differences in the perceptions and behavior of people in organizational settings is recognized.

A technique recently developed by the senior author and successfully employed by all three of the authors, helps to overcome the problems described above by providing a convincing demonstration of the phenomenon and importance of individual differences in organizations. It uses a theory which is practical, easily understood, and of direct relevance to practitioners. Moreover, the exercise encourages a relatively safe level of self-disclosure that enhances a climate of openness in the class.

\section{The Theory}

John Holland's (1973) theory of vocational preferences maintains that occupational preferences are not random, but rather reflect stable characteristics of personality. The theory is generically simple, being based on six major personality categories; ideographically complex, with 720 possible permutations of the six basic personality types; and conceptually elegant, in that each of the basic types are related to the others in an integrated hexagonal model.

Briefly, the six primary personality types ${ }^{1}$ (Holland, 1979, 1978, 1973) are:

Realistic Type - This type is characterized by preferences for the practical and down-to-earth. Such persons prefer positions requiring manual activities rather than working with people or data. They are often described by such adjectives as "shy," "practical," "persistent," and "masculine."

Investigative Type - Persons in this group prefer activities requiring analytical study. They are more inclined to introspection and understanding than to action. Such adjectives as "rational," "intellectual," "introverted," and "task-oriented" are used to describe investigative persons. The sciences or mathematics are preferred occupations.

Artistic Type - Artistic persons are like Realistic and Investigative types in being asocial, but differ in their preferences for such artistic activities as painting, music, or creative writing. They prefer to work on ambiguous problems which allow individualistic

${ }^{1}$ Users of this exercise are encouraged to consult Holland (1973) for a more detailed explanation of the major personality characteristics. 
expression. Descriptors applied to such persons typically include "emotional," "idealistic," "complicated," and "creative."

Social Type - The Social type consists of individuals who desire to work primarily with and through other people. Their preferences are for activities in which they can teach, aid, or in some way enrich others. Common Social occupations are counseling, social work, and education. Such people are often described as "friendly," "cooperative," "understanding," and "persuasive."

Enterprising Type - Enterprising persons, like Social ones, prefer working with people rather than with things or objects, but unlike Social types, they have strong desires to control the behavior or activities of others. Their work often includes manipulation of people to achieve organizational or economic goals. Verbal skills, "selling," and leading others are typical. They are often described as being "ambitious," "selfconfident," "controlling," and "aggressive." Common Enterprising professions include politics and business management.

Conventional Type - Organized and "rational," Conventional types often respond well to structured activities in which they play a subordinate role. They are frequently described as being "conforming" and "conscientious." Such people assume positions requiring structured activities, often using data or machines. Some common conventional occupations include bookkeeper, accountant, and payroll clerk.

The above descriptions represent the "pure" types. Holland (1973) notes that individual occupational personality types are typically combinations of the major types (e.g., Investigative-Realistic-Enterprising), and therefore each person's profile must be considered individually, not simply as a dominant single "type."

\section{PROCEDURE}

\section{Advance Preparation}

Students are asked to complete and bring to class one of the instruments developed for measuring Holland's (1973) constructs. (We have used the Self Directed Search (SDS), although others are available.) ${ }^{2}$ The SDS was created especially for occupational self-exploration, so that the services of a trained

\footnotetext{
${ }^{2}$ Among the alternative forms are the Vocational Preference Inventory (VPI) (Holland, 1978), and a recently developed VPI short form which has been demonstrated to have validity and reliability characteristics similar to the VPI long form (Lowman and Schurman, in press). It should be noted, however, that a "key" is required for scoring the VPI, whereas the SDS is self-scoring.
}

counselor are not essential for its use. It also has the advantage of being relatively inexpensive. ${ }^{3}$

Instructions on the instrument should be supplemented with the following:

(1) Please complete the form by yourself, being as honest as you possibly can, to ensure your responses reflect your actual feelings and opinions rather than how you think you "should" respond.

(2) Please respond to the occupational choice portion of the instrument without regard to your current abilities. That is, answer "yes" if you think you would like to be a concert pianist regardless of whether you have musical training or ability.

(3) If two or more of your final top three scores on Holland's scales are tied, attempt to break the tie by reviewing your answers in these areas.

(4) Bring the completed form with you to the next class meeting.

The completed SDS provides each student with three Holland high point scores. These reflect the personality "type." The letters appear on each student's profile in descending order of importance. For instance, a student may be an ESC (Enterprising, Social, and Conventional, in that order), or an IRA, CES, RSI, etc.

\section{In-Class Exercise}

This exercise requires one to two hours. If a shorter time period is available, it can be conducted in two consecutive class periods.

On the day of the event, the instructor's first task is to form participants into five to eight person groups of maximum homogeneity using the three-letter Holland type indicators. This can be done relatively quickly (in five minutes or less) by eliciting a show of hands of people in the various groupings. In the authors' experience, OB classes, whether in professional schools or Psychology departments, have had a large portion of students in the Enterprising, Conventional and Social categories. Consequently, to form optimum sized groups it may be necessary to use the first two or even all three letters (e.g., all ESIs, all ESCs, all ESs, etc.) to create groups. In the case of the less wellrepresented groupings (typically " $R$ " and " $A$ "), only the first letter may need to be used to obtain a group of suitable size. The size of the groups may vary somewhat depending upon the total class size and the

${ }^{3}$ The 1982 cost of the SDS, for both the SDS and the Occupations Finder, ranges from $\$ .65$ to $\$ .77$ each depending on the quantities ordered. 
instructor's preferences, but a minimum class size of 20 to 25 is probably required to have all types represented. We have had little difficulty with groups as small as two and as large as nine.

Once groups are formed, each is sent to a separate room, nearby hallways, or to relatively quiet areas of the same classroom, each with the same assignment:

(1) Determine, in about 20 minutes, what the members of your group have in common which causes them to be in your particular group.

(2) Take note of what these commonalities are, and select a spokesperson to describe them to the assembled class when we reconvene.

(3) Pay attention to the processes through which the decisions about the commonalities among you are made.

In some cases, it may be desirable to remind groups that their task is to determine what the members have in common, not to conduct a critique of the instrument.

\section{Class Presentation}

Following the 20 minute sessions, the groups return to the classroom and are invited to observe and learn inductively about individual differences based upon the groups' findings, the processes each used, and the manner of presentation.

Each group's spokesperson is then asked to describe, in about five minutes, what members of their group found they had in common, any interesting differences which may have emerged, how the group organized itself to perform the task, and how the spokesperson was selected. An additional one or two minutes per group is allowed for other members of each group to supplement the points and observations made by their spokesperson. If the number of groups is large, the instructor may wish to request commentary from only a few representative groups, to avoid repetition and excessive use of class time.

\section{Theory and Integration}

After all groups have presented their reports, Holland's theory of individual differences is formally presented. By this point, the nature of the class' differences is clear to the participants, and Holland's theory and the concept of individual differences are easily understood. Although a formal discussion of Holland's theory is desirable to explain such features as how the various types relate to each other, the class discussion and examination of the exercise can often take the place of a formal lecture on individual differences and their relevance for managing organizations.

With relatively little prompting, class members often come to recognize not only the differences in the characteristics outlined by group spokespersons, but also manifestations of those differences in the mannerisms of the spokespersons, and the descriptions of what happened in the groups in such areas as group structure, communication patterns, and power relationships. Instructors can also help the class recognize and understand any differences which may have occurred within groups, while at the same time pointing out the possible imperfections of the theory. This is especially important to prevent students from placing undue emphasis on their results or stereotyping themselves or others. The observed differences may often be understood by noting the variation in the second and third letters of the SDS "types," even though the dominant theme (the first letter) was the same among group members.

The instructor may wish to conclude with a few summary comments. Among others, the following points can be made:

(1) Individual differences, such as those observed in this session, help to demonstrate a few of a person's many characteristics and why people are more likely to opt for and be more proficient at certain tasks and occupations, while poorly suited to others.

(2) These individual differences influence people's perceptions of their environments. Thus, "personality clashes" may result not only from the direct incompatibility of types, but also from the impact of individual differences on a person's reality construction.

(3) These perceptual differences may have marked effects on variables such as a person's preferred communication style, desire to interact with or to avoid others, preferred leadership style, tolerance of ambiguity and preference for various organizational rewards. These characteristics thus have a profound effect on managerial style and potential sources of interpersonal conflict. The exercise may also serve as a good source of example and discussion later in the course when conflict, communication, and leadership are examined.

(4) The instructor should take pains throughout the exercise to emphasize that no type is superior to another and that each makes a unique contribution to an organization. 


\section{Group Presentations}

The group presentations we have observed were characterized by openness, humor, and spontaneity. Even though the students did not know each other very well early in the term when the exercise was used, they quickly and enthusiastically entered the discussions and presentations, soon recognizing that they were indeed observing marked individual differences within the class.

The groups in each class differed somewhat in their presentations, but there were many commonalities. Perhaps most important for the success of the exercise, differences between groups were marked and usually immediately apparent to the class. These differences were in at least three areas: the within-group similarities among participants, the ease or difficulty with which the group was able to organize itself, and the mannerisms of the group spokesperson. The following are typical of the presentations we have encountered thus far in using this exercise with MBA classes:

Investigative: Persons in these groups quickly acknowledged that they tended to be introverts, and few volunteered for the role of spokesperson. There was also ready agreement that they were individualists who avoided community involvements, that they were analytical by nature, and that most had received undergraduate degrees in mathematics, engineering, or other hard sciences. They frequently described their members as being logical, preferring abstract to manual activities, and preferring individual over group sports activities.

Social: These groups were notable for their straying from the assigned task. One observed: "We were having so much fun, we didn't get around to finishing the assignment." All agreed, however, that being involved with other people was of maximum importance in their lives. They saw themselves as being openminded and creative, and preferred careers in such areas as personnel work and consulting. One group unintentionally demonstrated their concern for other people by giving up their discussion room to a larger group.

Enterprising: These have always been the largest groups in the MBA classes. Although the groups differed depending on the second or third letter in their
Holland profiles, most members' behavior fit the expected Holland description. These groups had trouble selecting a spokesperson, not for want of volunteers, but rather because too many group members were competing for the role. Enterprising persons reported that they were business oriented, high pressure, inclined toward wanting to be leaders rather than followers, and to have power and control over whatever occurred. Many wanted to own a business of their own or to be in sales. These groups were also notable for their clear presentations, engaging banter with the audience, and the obvious ease and enjoyment they were experiencing in their role as spokespersons.

Conventional: Although many members of these groups did not like the name "conventional," most described themselves in ways consistent with the theoretical description. Their presentations were orderly (e.g., "We find that we have six things in common. They are. . ."). All groups described themselves as being well organized, orderly, conforming, liking and having prior experience with office work, and having a preference for work in the accounting or financial aspects of business.

\section{Conclusion}

The exercise discussed here has been used to date in eight different classroom settings. The results, with few exceptions, have provided convincing illustrations of the usefulness of Holland's theory and more importantly, of the reality of individual differences, including what they look and "feel" like. The exercise accomplishes these goals in a manner that is very difficult for students to deny or avoid, and in a way that even the most resistant students are likely to remember.

\section{References}

Holland, J. L., Making Vocational Choices: $A$ Theory of Careers. Englewood Cliffs, New Jersey: Prentice-Hall, Inc., 1973.

Holland, J. L., Vocational Preference Inventory (Revised). Palo Alto: Consulting Psychologists Press, 1978.

Holland, J. L., The Self-Directed Search Professional Manual. Palo Alto: Consulting Psychologists Press, 1979.

Lowman, R. L., and Schurman, S. J., "Psychometric Characteristics of a Vocational Preference Inventory Short Form." Educational and Psychological Measurement, 1982, 42, in press. 